\title{
THE FOUNDING OF
}
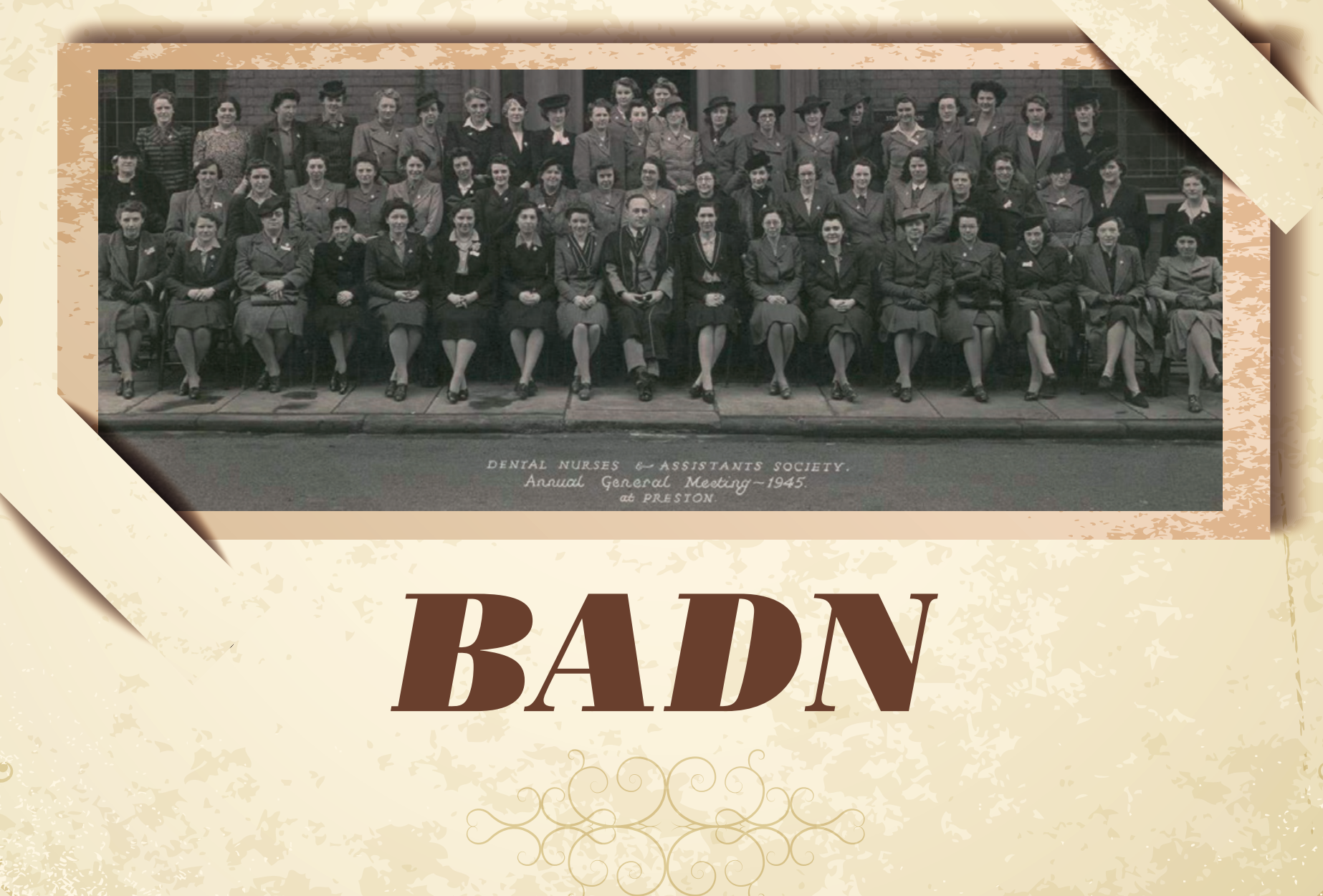

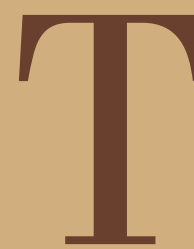

he Association was

founded in 1940 in Leyland (Lancashire) by the dentist PE Grundy and his dental surgery assistants, Amelia White and Madeleine

'Bunty' Winter, who became the first General Secretary, and was originally called the 'British Dental Nurses' and Assistants' Society'.

\section{Madeleine Winter}

In 1946 a full time General Secretary, Rita Methven, was appointed, replaced two years later by Jean Smith who remained in post until 1985. The Association remained in the North West, moving first to premises in
Poulton-le-Fylde, then to various premises in Fleetwood and is now based in ThorntonCleveleys. Jean Smith retired from the Association in 1985 (although she continued working for the Exam Board until 1991) and was replaced by Sue Adams (nee Ward) in 1985 and then current Chief Executive Pam Swain in 1992.

\section{The 1945 AGM}

For the first ten years, all Presidents of the Association were male dentists, but in 1950 Beatrice Green was the first President to be female and a dental surgery assistant (as dental nurses were then known). Since then, there have been 1 male and 52 female
Presidents - all DSAs/dental nurses. The Presidential term of office was for one year until 1994 when it extended to two years.

The first Journal was published in the mid-forties, and changed its name from 'The British Dental Surgery Assistant' to the British Dental Nurses' Journal in 1994.

In 1943, the Association founded the British Dental Nurses' and Assistants' Examining Board and held the first examination - only dentists were allowed to be examiners until 1978! The Board changed 
its name in 1988 to the National Examining Board for DSAs (NEBDSA) and again in 1994 to the National Examining Board for Dental Nurses (NEBDN). It became a completely separate entity in the 1980s and is completely independent of the Association. Until that point, the Association, the Exam Board and the Register had all been run out of the same office using - in those pre-computer days - arrived at $8 \mathrm{am}$, training was very early in the morning!

In October 1964 the Association established the Voluntary National Register to encourage DSAs to train and become qualified - the original registration fee was $£ 1$. In the late 1970s, the Register became the responsibility of the Registration Committee of the GDC's Dental Surgery Assistants' Standards and

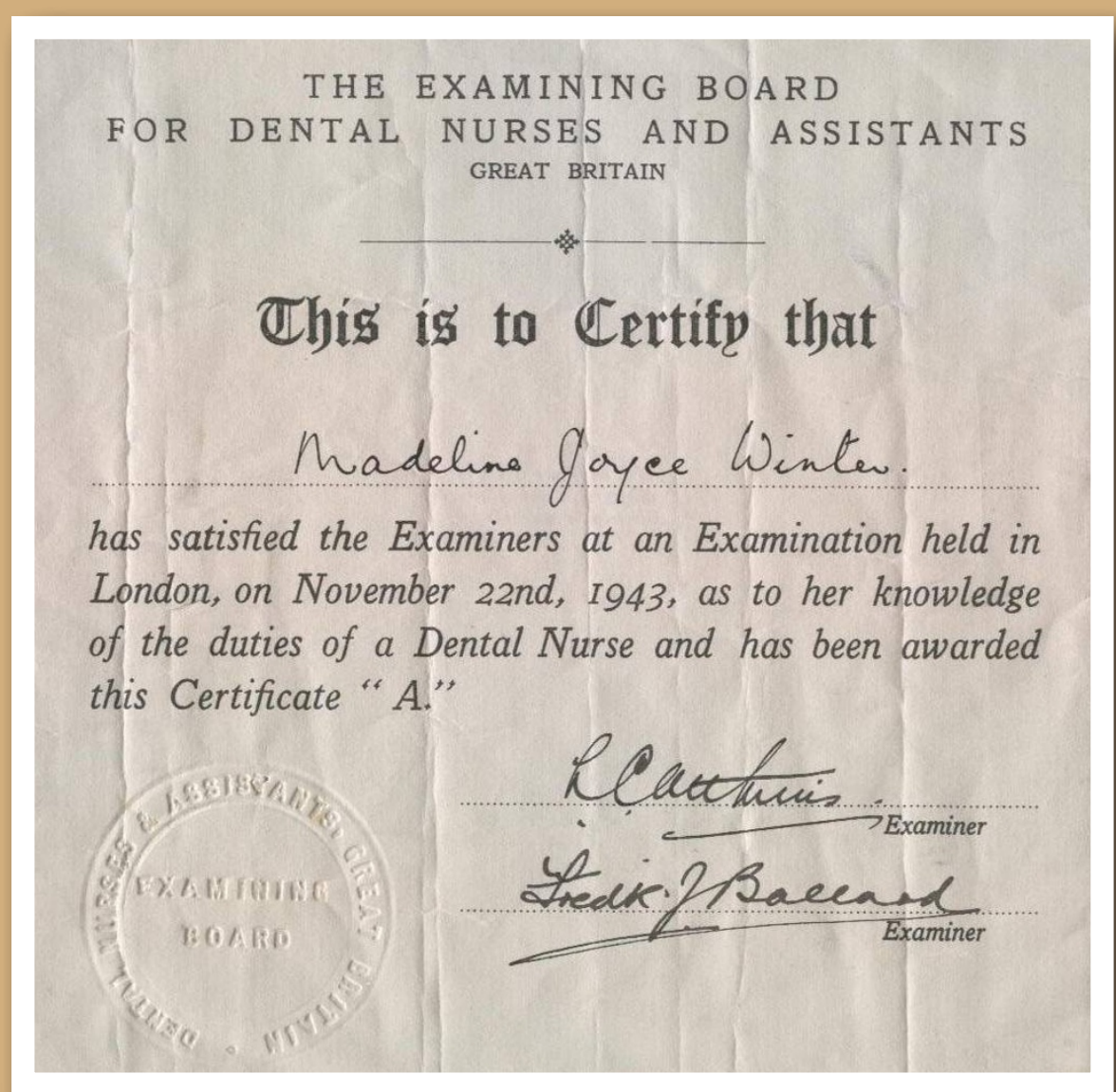

\section{'TRAINING TOOK PLACE IN THE}

\section{PRACTICE EVERY MORNING BEFORE \\ SEEING PATIENTS. AS THE FIRST PATIENTS

\author{
ARRIVED AT BAM, TRAINING WAS
} \\ VERY EARLY IN THE MORNING!'}

index cards and three different coloured pens - green for the Register, red for the Exam Board and blue for the Association!

Madeleine Winter was a candidate in the very first Exam (see her qualification certificate above) - she told us that training took place in the practice every morning before seeing patients. As the first patients
Training Advisory Board (DSASTAB, later DNSTAB), although the day to day administration of the Register was carried out by the Association until it closed in 2005 .

Up till 1994, dental nurses had been known officially as 'Dental Surgery Assistants' or 'DSAs', but at the Association's AGM in 1994, members voted unanimously to change the title to 'dental nurse' (which was what most patients and the general public called them anyway) and the name of the Association from the 'Association of British Dental Surgery Assistants' to the 'British Association of Dental Nurses. The Exam Board and STAB followed suit and amended their names to reflect the change in title.

In 1995, in preparation for statutory registration and in response to the need to ensure high quality dental nurse training the Training Advisory Service (TAS) was formed by the Association, with financial assistance from DNSTAB. TAS then became an independent body, with administrative support provided by NEBDN, providing voluntary accreditation of dental nurse training courses; and is now NEBDN's Quality Assurance department which monitors and accredits courses leading to NEBDN qualifications.

In 1999 the GDC took the historic decision to agree in principle to the statutory registration of all Professionals Complementary to Dentistry or PCDs (as they were then to be called), including dental nurses. It took until 2006 for registration to actually be implemented; by then what had originally been known as 'auxiliaries' and then PCDs (hygienists, therapists, technicians and dental nurses) had been designated Dental Care Professionals or DCPs. As of 2008, only dental nurses with an approved qualification may register with the GDC, although the 2006-08 window allowed those with specified experience to 'grandparent' onto the Register.

During the last 75 years, BADN has moved forward and adapted to meet the changing needs of dental nurses. It now offers indemnity cover to members who are eligible, as well as Continual Professional Development (CPD) in the Journal, which is now digitally accessed so members can read it anywhere they have a computer, tablet or phone. Initial legal advice is offered via a telephone helpline, as is counselling for members experiencing difficult times in their personal or professional lives. The range of member benefits is constantly revised to ensure that what is available to members is relevant and contemporary, and gives a wide ranging and eclectic selection discounts and special offers to enable members to save money in both their personal and professional lives. The latest development is an e-membership for student dental nurses.

At the 75th anniversary celebration at the In \& Out Naval \& Military Club, BADN President Fiona Ellwood paid tribute to the founding members and looked to the immediate future and beyond. Fiona said: 


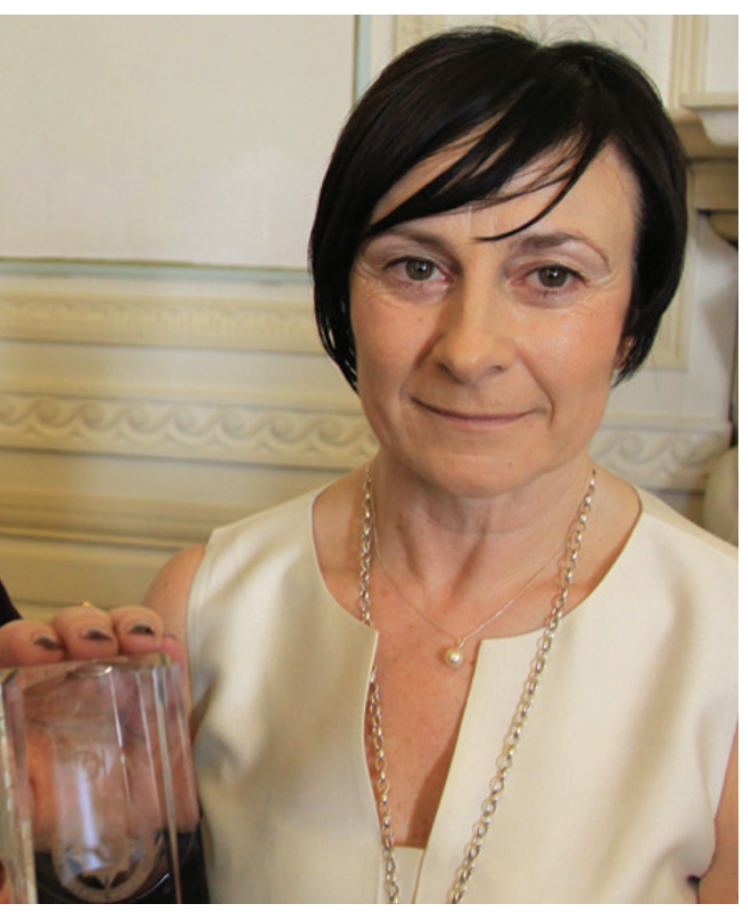

BADN President Fiona Ellwood with the commemorative glass presented by the British Dental Industry Association

\section{'BADN IS PROUD TO HAVE OFFERED}

INFORMATION, ADVICE AND SUPPORT

TO DENTAL NURSES FOR THREE-QUARTERS OF

A CENTURY - AND LOOKS FORWARD TO

CELEBRATING ITS CENTENARY IN 2040!'

'It is right that we look back and recognise those who have paved the way, but it is equally important to look to the future. I thank you on behalf of the British Association of Dental Nurses for joining us in our celebrations, I know many of you have travelled far to be with us. Many of you have been part of this journey and will know how much the role of the dental nurse has changed over the years, when registration finally came to fruition nobody could have imagined the sheer impact that it would have and indeed what it will mean for the future, but it is one with much greater opportunity and who knows where it will end. It is a privilege to be in post at such a momentous time for the Association, nevertheless this year will see the end of my tenure.

\section{Membership fees}

Student dental nurses are currently being offered a special rate of just $£ 10$ a year;

Full Membership for Registered Dental Nurses starts at £50 a year without indemnity or $£ 88.41$ with basic indemnity cover.

For more information on BADN membership, go to www.badn.org. uk or call 01253338366.

bdjteam201588

\section{FLASH INTERVIEW}

\section{Karen Healy- oconnor \\ Karen is a \\ 23-year-old \\ dental nurse \\ at Claremont \\ Dental Practice \\ in Manchester. \\ She lives \\ with her little \\ boy Shea.}

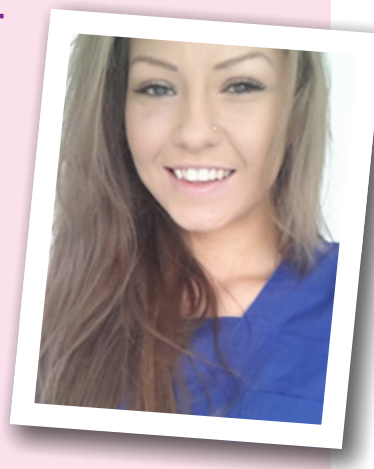

Name: Karen Healy-OConnor

Age: 23

Job title: Qualified dental nurse.

Town: Manchester.

Most recent workplace: Claremont

Dental Practice.

Marital status: Single.

Any children? One little boy called Shea. He's two.

How long have you worked in dentistry? Seven years.

Why did you choose dentistry for your career? I was 16 looking for a job as I was unsure what course to take in college and there happened to be a vacancy for a trainee nurse at a local practice.

What do you like best about dentistry? Working with a variety of people and making a difference to a patient - it is super rewarding.

What is the most challenging part of your job? The most challenging part is always having to be ready for anything. One day is never the same as the next.

What do you like to do outside work? I love to spend time with my little boy and keep fit.

Tell us a secret. I hate sharing food. I'd rather buy you 10 bags of malteasers than share one of mine!!

What do you like about BDJ Team? Keeps you up to date and provides great CPD.

What three things could you not live without (besides people)? Domino's pizza, rum and of course a toothbrush!

bdjteam201589 